\title{
Correlation between the results of three physical fitness tests (endurance, strength, speed) and the output measured during a bicycle ergometer test in a cohort of military servicemen
}

\author{
Stefan Sammito ${ }^{1,2^{*}}$, Nils Gundlach ${ }^{3}$ and Irina Böckelmann ${ }^{2}$
}

\begin{abstract}
Background: Physical fitness tests are widely used to assess endurance, sprint ability, coordination and/or strength. The objective of the present study was to analyze the degree to which the results of the Bundeswehr Basis Fitness Test (BFT)-a physical fitness test comprising a sprint test $(11 \times 10-\mathrm{m}$ shuttle test), a flexed-arm hang test and a 1000-m run-are consistent with the output measured during a bicycle ergometer test. The number of false-positive and false-negative results with regard to the assessment of physical fitness were also examined.

Methods: As part of a retrospective study, health assessments from 323 reenlistment examinations were evaluated regarding the output measured during a bicycle ergometer test and compared with the BFT results of the candidates.

Results: Overall, a good correlation was shown between the bicycle ergometer test results and the results achieved in the BFT disciplines. All three disciplines of the BFT showed a highly significant correlation with the relative output achieved during the bicycle ergometer test $(P<0.001)$, and also, the overall BFT score was highly significantly correlated $(P<0.001)$. The overall rate of false-positive and false-negative results was $4.0 \%$.

Conclusions: The BFT results measured in the three physical fitness test items were highly correlated with the output measured during the bicycle ergometer tests. The rate of false-positive and false-negative results was low. The test items thus represent an appropriate measurement instrument because the test items require few equipment and less time. Additionally, a large number of subjects can be assessed. We suggest that it would be more useful to assess the physical fitness of this special group exclusively on the basis of the BFT instead of using the bicycle ergometer test.
\end{abstract}

Keywords: Physical fitness, Military, Ergometer test, Bicycle, Treadmill

\section{Background}

Physical fitness tests are widely used to assess endurance, sprint ability, coordination and/or strength. Sets of various performance tests are especially useful in areas where, outside of a competitive sports context, a number of these abilities are essential for the accomplishment of

\footnotetext{
* Correspondence: drsammito@web.de

'Bundeswehr Medical Service Headquarters, Section Health Promotion, Sports and Nutrition Medicine, Koblenz, Germany

${ }^{2}$ Otto von Guericke University Magdeburg, Medical Faculty, Department of Occupational Medicine, Magdeburg, Germany

Full list of author information is available at the end of the article
}

tasks. For years, the level of physical fitness of military applicants and active soldiers-who must have a generally high fitness level [1-3]-has been evaluated based on national military fitness tests, both in Anglo-American countries [4-8] and in Europe [9, 10]. Because of countryspecific particularities, the tests comprise different items. In most cases, however, endurance, strength and speed are assessed.

In 2010, the Basic Fitness Test (BFT) became compulsory in the German Armed Forces to evaluate physical fitness outside of medical examinations [11]. Every soldier 
must annually pass this physical fitness test, which includes a sprint test $(11 \times 10-\mathrm{m}$ shuttle test $)$, a flexedarm hang test and a 1000-m run. The entire test must be completed in $90 \mathrm{~min}$. Minimum test requirements (see Table 1) must be fulfilled regardless of gender or age [11]. See the "Methods" chapter for a detailed description of the individual test items. However, the BFT is not mandatory for the reenlistment of a soldier.

In addition, the German Armed Forces still conduct bicycle ergometer tests as part of their medical examinations for reenlistments, as is customary in other armed forces. Pilots, for example, undergo bicycle ergometer tests, not only to exclude cardiovascular diseases but also to confirm that they meet minimum physical requirements $[12,13]$. While ergometer tests can assess physical fitness in a standardized way, regardless of weather conditions, they only provide information about a subject's treadmill- or bicycle-specific fitness.

Because soldiers need more than maximal aerobic power for the successful performance of their military tasks, and the bicycle ergometer test only assesses this skill, it is important to compare the results of the bicycle ergometer test with the results of the BFT to determine if the physical fitness of soldiers can be assessed using only one test. Therefore, the objective of the present study is 1) to analyze the degree to which BFT results are consistent with the output measured during bicycle ergometer tests and 2) to record the rate of false-positive and false-negative results in the assessment of physical fitness obtained during bicycle ergometer tests compared with the BFT.

\section{Methods}

As part of a retrospective study, health assessments from 323 reenlistment and "survival on operations" examinations conducted at the Augustdorf Major Medical Clinic with Specialty Services, Detmold branch, Internal Medicine clinic were evaluated (from 2010 to 2012) and compared with the results on the BFT. "Survival on operations" examinations were included to increase the overall number of data sets, as they were largely identical to reenlistment examinations and were all conducted on young military personnel. Only men were included in this study because only a small number of women served in the German Army Forces.

Table 1 Minimum pass requirements of BFT

\begin{tabular}{ll}
\hline Athletic discipline & Minimum requirements \\
\hline $11 \times 10-\mathrm{m}$ sprint test & $\leq 60 \mathrm{~s}$ \\
Flexed-arm hang & $\geq 5 \mathrm{~s}$ \\
$1000-\mathrm{m}$ run & $\leq 390 \mathrm{~s}$ \\
\hline
\end{tabular}

Minimum pass requirements of the Basic Fitness Test [11]
On average, the subjects were $24.3 \pm 2.6$ years old, $179.7 \pm 6.8 \mathrm{~cm}$ tall and weighed $82.5 \pm 11.7 \mathrm{~kg}$ (BMI: $25.5 \pm 3.2 \mathrm{~kg} / \mathrm{m}^{2}$ ). Their average absolute and relative output during the bicycle ergometer test was $239 \pm 31$ watts and $2.9 \pm 0.4$ watts, respectively, per kilogram of body weight. The average BFT output was $42.0 \pm 3.6 \mathrm{~s}$ (11 × 10-m run), $44.3 \pm 19.8 \mathrm{~s}$ (flexed-arm hang) and $261.8 \pm 39.3 \mathrm{~s}$ (1000-m run).

The project was given a positive assessment by the Bundeswehr Medical Service, is registered under the research number $01 \mathrm{KS}-\mathrm{S}-631314$ and meets the international ethical standards [14].

\section{Bicycle ergometer test}

Ergometer tests conducted on a bicycle ergometer were analyzed for the maximum output achieved and for the relative output per kilogram of body weight. The tests were performed according to a standardized protocol, starting at 100 watts and increasing by 50 watts every $2 \mathrm{~min}$.

\section{BFT}

The BFT data of all soldiers were provided by their companies and correlated with the bicycle ergometer test output. The data were collected during the routine BFT in the same year of the ergometer test.

The BFT comprises three individual physical fitness test items, which must be completed in a fixed sequence [11] and is observed by an instructor. The first test is the $11 \times$ $10-\mathrm{m}$ sprint test. Subjects start lying prone on an exercise mat with their arms crossed behind their backs. After the start signal, they run around a marker at a $10-\mathrm{m}$ distance and return to the mat. Once subjects return to the mat, they must lie down again and clap their hands behind their backs. This process is repeated five times. After lying down for the fifth time, subjects stand up for a final run to the $10-\mathrm{m}$ marker, where they complete the $11 \times 10-\mathrm{m}$ sprint test. Time was measured to one decimal place.

During the flexed-arm hang test, the subjects must keep their chin above a pull-up bar with their arms flexed and hold their body weight in a static position with their hips and knees extended. The hands should be placed on the bar shoulder-width apart. Timing starts when the start signal is given and ends when the chin drops below the bar.

The 1000-m run is completed in a group on a $400-\mathrm{m}$ running track. Timing starts with the start signal and ends when the subjects cross the 1000-m marker.

The overall score is calculated based on the absolute measurements of every discipline in seconds. These are converted into points with 100 points equaling the minimum requirement with the following set phrase:

Points $11 \times 10-\mathrm{m}$ sprint run $=1100-(16.667 \times$ time sprint test $[\mathrm{s}])$; 
Points flexed-arm hang test $=75+(5 \times$ time flexed-arm hang test $[\mathrm{s}])$; and

Points $1000-\mathrm{m}$ run $=100+((390-$ time $1000-\mathrm{m}$ run $[\mathrm{s}]) \times 1.81818181)$.

All three disciplines are weighted equally in the calculation of the overall score.

\section{Data collection and statistics}

The data were stored in a Microsoft Access $2010^{\circ}$ database in pseudonymised form and evaluated using IBM SPSS Statistics 22. In addition to descriptive statistics (mean value, standard deviation), a fourfold contingency table was used to calculate false-positive and false-negative results; a Pearson's correlation was conducted, and a linear regression analysis was run. Differences between groups were analyzed using an independent samples $t$-test. A $P$-value lower than 0.05 was considered statistically significant.

\section{Results}

Out of 323 soldiers, 310 soldiers passed both the bicycle ergometer test and the BFT. Two soldiers were evaluated as physically fit during the bicycle ergometer test but did not pass the BFT. Eleven soldiers were not able to meet the minimum requirements of the bicycle ergometer test but passed the BFT. In $96.0 \%$ of all cases, the subjects passed both the bicycle ergometer test and the BFT (Table 2).

For the endurance test only, a good correlation was shown between the bicycle ergometer test results and the results achieved in the BFT disciplines $(r=-0.237$, $P<0.001)$. The $11 \times 10-\mathrm{m}$ sprint test and the flexedarm hang showed no correlation with the absolute output ( $r=-0.068, r=0.009$, respectively) and were considered statistically insignificant with $P$-values $>0.05$ (Table 3 ). The correlation of the overall BFT score with the absolute output measured during the bicycle ergometer test was significant $(r=0.132, P=0.018)$.

Based on the correlations of the BFT results in the three disciplines and the overall BFT score with the output measured during the bicycle ergometer test in relation to body weight, we conclude that with regard to all individual disciplines, as well as to the BFT score, the correlations were highly significant $(11 \times 10$-m sprint test $r=-0.325$, flexedarm hang $r=0.417$ and $1000-\mathrm{m}$ run $r=-0.437$, BFT in

Table 2 Fourfold contingency table of the results of BFT and ergometry

\begin{tabular}{lll}
\hline & Failed BFT & Passed BFT \\
\hline Failed cardiac stress & 0 & $\mathbf{1 1}$ \\
Passed cardiac stress test & $\mathbf{2}$ & 310 \\
\hline
\end{tabular}

Fourfold contingency table; false positive and false negative results are highlighted in bold letters
Table 3 Correlation between BFT and absolute output on bicycle stress test

\begin{tabular}{lrll}
\hline Athletic discipline & \multicolumn{1}{l}{$r$} & $P$ & $R^{2}$ \\
\hline $11 \times 10-\mathrm{m}$ sprint test [s] & -0.068 & 0.224 & 0.005 \\
Flexed-arm hang [s] & 0.009 & 0.873 & 0.000 \\
1000-m run [s] & -0.237 & $<\mathbf{0 . 0 0 1}$ & 0.056 \\
Total output [score] & 0.132 & $\mathbf{0 . 0 1 8}$ & 0.017 \\
\hline
\end{tabular}

Correlation between the measured BFT output/score and the absolute output measured during the bicycle stress test including regression analysis variance; significance results are highlithted in bold; $n=323$

total $r=0.538$, all $P<0.001$, Table 4 ). In Fig. 1 , this is illustrated by scatter plots with regression lines.

\section{Discussion}

The results presented here demonstrate, based on a large sample, a significant correlation between the individual disciplines of the BFT $(11 \times 10-\mathrm{m}$ sprint test, flexed-arm hang and 1000-m run) and the output measured during a bicycle ergometer test completed by the examined cohort of young subjects. The results also show that the BFT provides a similar assessment of physical fitness. The $4.0 \%$ false-negative and false-positive rate, however, showed that the bicycle ergometer test, in contrast with the BFT, which was designed to test more than only maximal aerobic power, resulted in an underestimation of the level of physical fitness and fitness for service. In addition to the size of the sample, the diversity of the areas of physical fitness examined is a distinguishing feature of the present study.

Bicycle ergometer tests are controversial as part of assessments $[15,16]$. The reliability of these tests is rated as low in regard to excluding cardiac arrhythmia and detecting coronary heart diseases in a young and healthy cohort $[17,18]$. Bicycle ergometer tests as part of medical check-ups for athletes are therefore not recommended under the age of 35 or 40 [19-24]. It is also widely accepted that bicycle ergometer tests are only suitable to evaluate bicycle-specific fitness [16]. Moreover, subjects with a higher body weight have the advantage that the impact of their additional weight is reduced in this evaluation [25]. Ergometer tests have advantages over separate physical fitness tests. They can be performed in a standardized way, independent of weather

Table 4 Correlation between BFT and relative output on bicycle stress test

\begin{tabular}{lrll}
\hline Athletic discipline & $r$ & $P$ & $R^{2}$ \\
\hline 11x10-m sprint test [s] & -0.325 & $<\mathbf{0 . 0 0 1}$ & 0.106 \\
Flexed-arm hang [s] & 0.417 & $<\mathbf{0 . 0 0 1}$ & 0.174 \\
1000-m run [s] & -0.437 & $<\mathbf{0 . 0 0 1}$ & 0.191 \\
Total output [score] & 0.538 & $<\mathbf{0 . 0 0 1}$ & 0.290 \\
\hline
\end{tabular}

Correlation between the measured BFT output/score and the relative power output (watts $/ \mathrm{kg}$ ) measured during the bicycle stress test including regression analysis variance; significance results are highlithted in bold; $n=323$ 

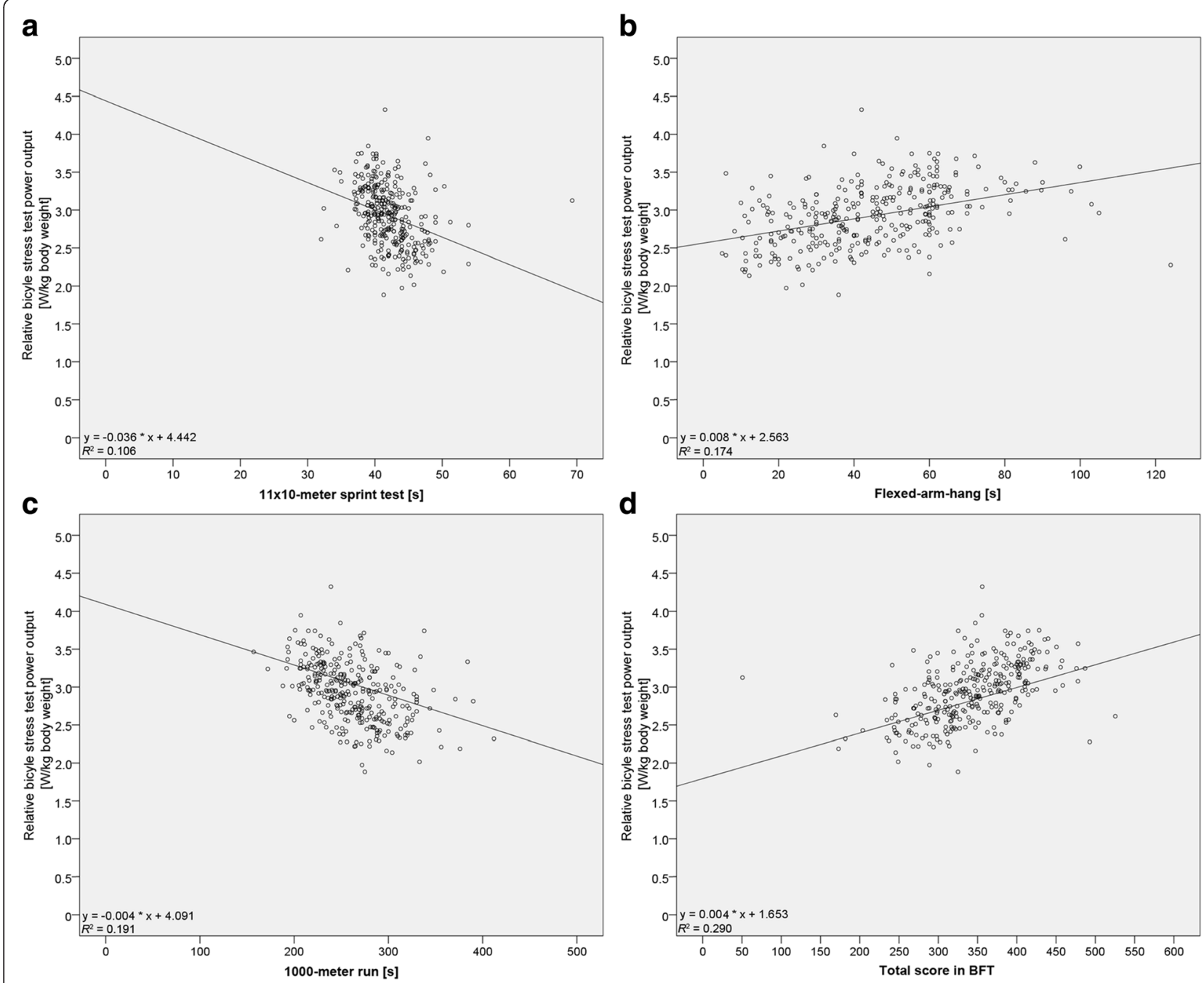

Fig. 1 Scatter plots of the correlations. Scatter plots of the results achieved in the sprint test (a), flexed-arm hang (b) 1000-m run (c) and total score of $\mathrm{BFT}(\mathbf{d})$ in correlation with the relative power output measured during the bicycle stress test and illustration of the relevant regression lines. $n=323$

conditions, and require little space. It should be noted, however, that they require more personnel.

The BFT presented here requires little effort because of its conditions. It merely requires a suitable gym for the sprint and the flexed-arm hang tests, as well as the necessary materials (mats, cones to mark the floor, pull-up bar) and a track suitable for running a 1000-m distance (e.g., a 400-m track). The high correlation of the individual BFT disciplines and the overall BFT score with the bicycle ergometer test (both in absolute values and relative to body mass) indicates that the BFT can be used as an alternative to bicycle ergometer tests. Because it targets the physical fitness skills of endurance, strength and speed, the BFT is the more suitable test procedure.

The high correlation between the individual BFT items and the bicycle ergometer test was confirmed for other tests as well. Williford et al. [13] analyzed the correlation between bicycle ergometer tests and maximal treadmill tests and found a correlation of $r=0.74$. The maximal oxygen uptake $\left(\mathrm{VO}_{2 \max }\right)$, however, was considerably lower during the bicycle ergometer test $(-17 \%)$. Basset et al. [26] also found comparability between bicycle and treadmill ergometer tests when examining 6 triathletes, 6 runners and 6 cyclists. They came to the conclusion that in both tests the heart rate and the percentage of the $\mathrm{VO}_{2 \max }$ were comparable. Jaskólska et al. [27] observed a high correlation $(r=$ 0.71-0.86) between these two types of ergometer tests as well in their examination of 32 male subjects. Carey et al. [28] did not identify any differences in the maximum heart rate and the $\mathrm{VO}_{2 \max }$ in the examination of 16 experienced triathletes, they did detect significant differences regarding the determination of the anaerobic threshold. Although we can generally assume a relatively good correlation between both test systems, we must take into consideration that both tests were conducted as stationary laboratory tests and that the majority of examined subjects were 
athletes who were well-trained in the relevant athletic disciplines.

In a study by Grant et al. [29], a very high correlation $(r=0.92)$ was observed in 22 young male subjects between the 12-min Cooper test and submaximal cycling output. The results of our study are consistent in this respect because we also observed a very high correlation between the 1000-m run and the bicycle ergometer test output.

The study of Grant et al. [29] and a study of Cairney et al. [30] note a high correlation between shuttle runs and bicycle ergometer tests. Grant et al. conducted a multi-stage progressive shuttle run test and detected a correlation of $r=0.86$ with the bicycle ergometer test while Cairney et al. examined children doing a 20-m shuttle run and found a correlation of $r=0.71$. These results are thus also consistent with the findings of the present study although the test structure referred to in the References section differs from the shuttle run $(11 \times$ 10-m sprint test) examined by us.

Whereas subjects with a higher body weight have an advantage in bicycle ergometer tests [25], a review carried out by Vanderburgh [31] showed that in the fitness tests common in the US Army, Air Force and Navy, subjects with lower body weight were able to perform better. The present study also demonstrates that weight has an influence on the results achieved during the flexedarm hang. Only the relative output measured during the bicycle ergometer test correlated with the flexed-arm hang output. In addition, regression analysis variance increased for all test items when the output in the BFT disciplines was compared with the relative output measured during the bicycle ergometer test. This is not surprising, as subjects with a higher body weight achieve considerably lower results in the flexed-arm hang test in particular, whereas in the bicycle ergometer test their results are higher in comparison.

This study does have some limitations. Because the data analysis was retrospective, ergometer test and BFT data were compared irrespective of how much time had passed between the tests. We can therefore not rule out that the physical fitness of the subjects had improved or worsened significantly during this period. Among other things, this could explain the number of false-negative and false-positive results. To provide reliable information on the correlation between the bicycle ergometer test and BFT output, a prospective randomized study with short intervals between the two tests should be conducted. This, however, was beyond the scope of this study.

Because the overall proportion of women in the German armed forces is low (approx. $10 \%$ ), only men were included in this study. Therefore, these results cannot be generalized to physical fitness examinations of women. Moreover, it is possible that the group of subjects on which the study is based is not representative of the respective locations. It is conceivable, for example, that only particularly unathletic or sick persons or, on the contrary, especially fit or healthy persons presented to the specialist clinic. This can be considered unlikely because many different locations and unit physicians have referred personnel to the Specialist Clinic for Internal Medicine for medical examination, and because an interim evaluation of the cohort of temporary career volunteers used for the analysis (comprising the assessments of the period from 2007 to 2010) includes both soldiers with a high level of physical fitness and a considerable number of soldiers that were unfit for service [32]. It can therefore be assumed that the overall sample of 323 soldiers has not been affected by significant selection bias through the referral/presentation of subjects.

\section{Conclusions}

It can be concluded that the BFT results measured in three physical fitness test items have a high correlation with the output measured during bicycle ergometer tests, that the rate of false-positive and false-negative results is low and that the test items therefore represent an appropriate measuring instrument because they require few equipment and less time, and a large number of subjects can be assessed. We suggest that it would be more useful to assess the physical fitness of this group of subjects exclusively on the basis of the BFT instead of using the bicycle ergometer test.

\section{Competing interests}

The authors declare that they have no competing interests.

\section{Authors' contributions}

SS and NG conceived the study and collected the data. SS and IB conducted the analysis and the interpretation of the data. All authors wrote the manuscript together and have read and approved the final manuscript.

\section{Author details}

${ }^{1}$ Bundeswehr Medical Service Headquarters, Section Health Promotion, Sports and Nutrition Medicine, Koblenz, Germany. ${ }^{2}$ Otto von Guericke University Magdeburg, Medical Faculty, Department of Occupational Medicine, Magdeburg, Germany. ${ }^{3}$ Bundeswehr Medical Clinic Rotenburg, Rotenburg (Wümme), Germany.

Received: 14 August 2015 Accepted: 12 April 2016

Published online: 23 April 2016

\section{References}

1. Knapik JJ, Reynolds KL, Harman E. Soldier load carriage: historical, physiological, biomechanical and medical aspects. Mil Med. 2004;169:45-56.

2. Knapik JJ, Rieger W, Palkoska F, Camp SV, Darakjy S. United States Army physical readiness training: rationale and evaluation of the physical training doctrine. J Strength Cond Res. 2009;23:1353-62.

3. NATO. Optimising operational physical fitness. Final Report of Task Group 019. RTO Technical report. TR-HFM-080. 2009. RTO/NATO. https://www.cso.nato.int/ pubs/rdp.asp?RDP=RTO-TR-HFM-080. Accessed 15 Apr 2016.

4. Knapik JJ. The army physical fitness test (APFT): A review of the literature. Mil Med. 1989;154:326-9.

5. Mitchell T, White ED, Ritschel D. Investigating the correlation of the U.S. Air Force Physical Fitness Test to Combat-Fitness: A women-only study. Mil Med. 2014;179:653-8. 
6. Vanderburg PM, Flanagen S. The backpack run test: a model for a fair and occupationally relevant military fitness test. Mil Med. 2000;165:418-21.

7. Whitehead PN, Schilling BK, Peterson DD, Weiss LW. Possible new modalities for the Navy Physical Readiness Test. Mil Med. 2012;177:1417-25.

8. Worden T, White ED. Modifying the U.S. Air Force Fitness Test to reflect physical combat fitness: one study's perspective. Mil Med. 2012;177: 1090-4.

9. Richmond VL, Rayson MP, Wilkinson DM, Carter JM, Blacker SD, Nevill A, et al. Development of an operational fitness test for the Royal Air Force. Ergonomcis. 2008;51:1461.

10. Wilkinson DM, Blacker SD, Richmond VL, Rayson MP, Bilzon JU. Relationship between the $2.4-\mathrm{km}$ run and multistage shuttle run test performance in military personnel. Mil Med. 2014;179:203-7.

11. Leyk D, Witzki A, Gorges W, Rohde U, Lison A, Rondé M, et al. Physical fitness, anthropometric measures, and risk factors in 18 to 35 year old soldiers: Results from the evaluation of the Basis-Fitness-Test (BFT). Wehrmed Mschr. 2010;54:278-82.

12. Hoffman JR, Kahana A, Chapnik L, Shamiss A, Davidson B. The relationship of physical fitness on pilot candidate selection in the Israel Air Force. Aviat Space Environ Med. 1999;70:131-4.

13. Williford HN, Sport K, Wang N, Olson MS, Blessing D. The prediction of fitness levels of United States Air Force officers: validation of cycle ergometry. Mil Med. 1994:159:175-8

14. Harriss DJ, Atkinson G. Ethical standards in sport and exercise science research: 2014 Update. Int J Sports Med. 2013;34:1025-8.

15. Elsner $\mathrm{KL}$, Kolkhorst FW. Metabolic demands of simulated fire-fighting tasks. Ergonomics. 2008:51:1418-25.

16. Heblich F, Sammito S. Strain of firefighters with self-contained breathing apparatus. How suitable are suitability tests? Zbl Arbmed. 2015;65:87-91.

17. Fuller CM, McNulty CM, Spring DA, Arger KM, Bruce SS, Chryssos BE, et al. Prospective screening of 5615 high school athletes for risk of sudden cardiac death. Med Sci Sports Exer. 1997;29:1131-8.

18. de Noronha SV, Sharma S, Papadakis M, Desai S, Whyte G, Sheppard MN. Aetiology of sudden death in athletes in the United Kingdom: a pathological study. Heart. 2009;95:1409-14.

19. Corrado D, Basso C, Schiavon M, Pellicia A, Thiene G. Pre-participation screening of young competitive athletes for prevention of sudden cardiac death. J Am Coll Cardiol. 2008;52:1981-9.

20. Corrado D, Pelliccia A, Bjørnstad HH, Vanhees L, Biffi A, Borjesson M, et al. Consensus statement of the study group of sport cardiology of the working group of cardiac rehabilitation and exercise physiology and the working group of myocardial and pericardial diseases of the European Society of Cardiology. Eur Heart J. 2005;26:516-24.

21. Löllgen $H$, Leyk D, Hansel J. The pre-participation examination for leisure time physical activity: General medical and cardiological issues. Dtsch Arztebl Int. 2010;107:742-9.

22. Maron BJ, Douglas PS, Graham TP, Nishimura RA, Thompson PD. Task Force 1: preparticipation screening and diagnosis of cardiovascular disease in athletes. J Am Coll Cardiol. 2005;45:1322-6.

23. Maron BJ. How should we screen competitive athletes for cardiovascular disease? Eur Heart J. 2005:8:516-24.

24. Pellicia A, Maron BJ. Preparticipation cardiovascular evaluation of the competitive athlete: perspectives from the 30-year Italian experience. J Am Coll Cardiol. 1995;75:1981-9.

25. Kindermann W. Recommendation for ergometry in medical practise. Dtsch Z Sportmed. 1987;38:244-88.

26. Basset FA, Boulay MR. Specificity of treadmill and cycle ergometer tests in triathletes, runners and cyclists. Eur J Appl Physiol. 2000;81:214-21.

27. Jaskólska A, Goossens P, Veenstra B, Jaskólski A, Skinner JS. Comparison of treadmill and cycle ergometer measurements of force-velocity relationships and power output. Int J Sports Med. 1999;20:192-7.

28. Carey DG, Tofte C, Pliego GJ, Raymond RL. Transferability of running and cycling training zones in triathletes: implications for steady-state exercise. J Strength Cond Res. 2009;23:251-8,

29. Grant S, Corbett K, Amjad AM, Wilson J, Aitchison T. A comparison of methods of predicting maximum oxygen uptake. Br J Sports Med. 1995; 29:147-52.

30. Cairney J, Hay J, Vedhuizen S, Faught B. Comparison of $\mathrm{VO}_{2}$ maximum obtained from $20 \mathrm{~m}$ shuttle run and cycle ergometer in children with and without developmental coordination disorder. Res Dev Disabil. 2010;31:1332-9.

31. Vanderburgh PM. Occupational relevance and body mass bias in military physical fitness tests. Med Sci Sports Exerc. 2008;40:1538-45.

32. Sammito $S$, Niebel I. Physical fitness in dependence on cardiovascular risk factors - an assessment of 20- to 30-year-old adults. Gesundheitswesen. 2013;75:59-62.

\section{Submit your next manuscript to BioMed Central and we will help you at every step:}

- We accept pre-submission inquiries

- Our selector tool helps you to find the most relevant journal

- We provide round the clock customer support

- Convenient online submission

- Thorough peer review

- Inclusion in PubMed and all major indexing services

- Maximum visibility for your research

Submit your manuscript at www.biomedcentral.com/submit
Biomed Central 